\title{
Heart protein expression related to age and sex in mice and humans
}

\author{
MADELEINE DIEDRICH ${ }^{1,4^{*}}$, JADRANKA TADIC $^{1 *}$, LEI MAO ${ }^{1}$, MAIK A. WACKER ${ }^{1}$, GRIT NEBRICH ${ }^{1}$, \\ ROLAND HETZER ${ }^{3}$, VERA REGITZ-ZAGROSEK ${ }^{2,3}$ and JOACHIM KLOSE ${ }^{1}$
}

\author{
${ }^{1}$ Institute for Human Genetics, Charité University of Medicine Berlin, D-13353 Berlin; ${ }^{2}$ Center for Gender in Medicine and \\ Center for Cardiovascular Research, Charité University of Medicine Berlin, D-10115 Berlin; ${ }^{3}$ Deutsches Herzzentrum Berlin, \\ D-13353 Berlin; ${ }^{4}$ FU-Berlin, Fachbereich Biologie, Chemie, Pharmazie, D-14195 Berlin, Germany
}

Received July 9, 2007; Accepted August 21, 2007

\begin{abstract}
Cardiovascular diseases are known to manifest different clinical symptoms in men and women. Basically this is due to gender-specific genotypes and sexual hormones. We studied gender specificity on the protein expression level in the mouse and human heart, with particular emphasis on the age-dependency of sex-specific protein expression. We first studied the heart proteome in female and male mice at 14 and 100 weeks of age using two-dimensional electrophoresis and mass spectrometry. Protein pattern comparison in young and old mice revealed 7 and 22 protein spots with sex-related expression profiles, respectively. Four proteins co-changed in both age groups. The variant protein spots were identified and revealed 10 distinct proteins and several isoforms thereof: $\alpha 1$-antitrypsin (3 isoforms), apolipoprotein A2 (2 isoforms), apolipoprotein A4 (3 isoforms), apolipoprotein E, apolipoprotein $\mathrm{J}$ (3 isoforms), carbonic anhydrase 2 (6 isoforms), desmin, nitrilase 1, peroxiredoxin 2 and Rho GDP dissociation inhibitor $\alpha$ ( 2 isoforms). More sex-related proteins were detected in old than in young mice. Through 2DE protein pattern and immunoblot comparisons, six of the variant proteins detected in mice were also observed to change in an age- and sex-dependent manner in the human heart. The age
\end{abstract}

Correspondence to: Professor Vera Regitz-Zagrosek, Deutsche Herzzentrum, Charité Universitätsmedizin Berlin, Augustenburger platz 1, D-13353 Berlin, Germany

E-mail:vrz@dhzb.de.

${ }^{*}$ Contributed equally

Abbrevations: 2DE, two-dimensional gel electrophoresis; ApoJ, apolipoprotein J; ApoA4, apolipoprotein A4; ApoE, apolipoprotein E; ApoA2, apolipoprotein A2; ROS, reactive oxygen species; CA2, carbonic anhydrase 2; P-RhoGDI 1, Rho GDP dissociation inhibitor $\alpha$; $\operatorname{Prdx} 2$, peroxiredoxin 2; AAT, $\alpha 1$-antitrypsin

Key words: two-dimensional gel electrophoresis, gender, age, apolipoproteins, $\alpha 1$-antitrypsin and/or gender-related proteins and species differences in this regard are discussed in terms of cardiovascular disease.

\section{Introduction}

Cardiovascular diseases such as coronary heart disease, arteriosclerosis, myocardial infarction and hypertension show significant sex- and age-dependency (1-4). In general, women develop cardiovascular diseases 10-15 years later than men $(1,5,6)$. For example, the probability for development of arteriosclerosis significantly increases with aging in both genders (1). However, because arteriosclerosis starts earlier in men, the number of diseased men in their $50 \mathrm{~s}$ is higher than that of women. Women and men also differ in cardiac remodelling with aging. Myocyte apoptosis and replacement fibrosis are more pronounced in aging male than in aging female hearts $(5,7,8)$. Furthermore, adaptation to mechanical load is better in females than in males, as has been shown in studies of myocardial hypertrophy under the condition of aortic stenosis $(4,9)$. Based on observations like these, it is well established that age and sex fundamentally influence the development of cardiovascular diseases. The expression of genes located on sex chromosomes and sexual hormones, such as estrogens and androgens, may explain sex-specific differences in disease phenotypes. However, in many ways the cellular and molecular mechanisms behind these differences remain elusive.

Proteomics is a fundamental approach in studying correlations between the molecular phenotypes of cells and the clinical phenotypes of organs. This technique has been successfully applied in elucidating the pathomechanisms behind cardiovascular disease (10-12). Using the mouse as a model organism, we studied the dependence of heart protein expression on age and sex under physiological conditions by two-dimensional electrophoresis (2DE) and mass spectrometry (13). Our goal was to identify proteins that are age- and sex-specifically expressed in the heart. For this purpose, a comparative study of female and male heart samples from C57BL/6 mice at two very distant age stages (young and old) was performed. Our large-gel 2DE technique allowed us to resolve over 3800 proteins (including protein isoforms) of the heart in a single 2D gel and offered a uniform and reproducible 
platform to investigate to what extent the difference in age and sex modifies protein expression. We investigated the proteins found to be expressed sex-dependently in the mouse also in the human heart. Our results offer a solid basis for the investigation of the role of gender- and age-related proteins in heart diseases.

\section{Materials and methods}

Animals and human tissues. The animal experiment protocol used in this study was approved by the ethics committee of Charité University of Medicine Berlin, according to the German Animal Protection Laws (TSchG). C57BL/6 mice were acquired from Charles River Germany (Sulzfeld, Germany). We used heart tissue from three mice in each of the following four groups: young females of 14 weeks of age, old females of 100 weeks of age, young males of 14 weeks of age, and old males of 100 weeks of age. Whole hearts were surgically extracted from the mouse thorax after swift decapitation. The heart was excised at the left ventricle and washed thoroughly with physiological salt solution to remove the blood completely. Subsequently the hearts were shock frozen in liquid nitrogen and stored at $-80^{\circ} \mathrm{C}$ until the protein extraction procedure. The investigation of human tissue conforms to the principles outlined in the Declaration of Helsinki. All patients gave written informed consent. Human left ventricular myocardial tissue was obtained from heart biopsies of 51- to 57-year-old women $(n=6)$ and 55- to 64-year-old men $(n=6)$. Idiopathic dilated cardiomyopathy was diagnosed by echocardiography. Biopsy material from subjects with significant hypertension or coronary artery disease, valvular, inflammatory, metabolic or congenital heart diseases, as established by cardiac catheterization, angiography and myocardial biopsy, was excluded.

Sample preparation for two-dimensional electrophoresis. Heart total protein extracts for two-dimensional gel electrophoresis were prepared as described previously (13). Briefly, whole mouse heart or $\sim 100 \mathrm{mg}$ of heart biopsy was ground in a mortar placed in a liquid nitrogen bath after adding the following: 2.2 parts (v/w) of $50 \mathrm{mM}$ Tris buffer $(\mathrm{pH} 7.5)$ containing $50 \mathrm{mM} \mathrm{KCl}, 20 \%$ (v/v) glycerol, 4\% (w/v) 3-[(3cholamidopropyl) dimethyl-ammonio]-1-propane sulfonate (CHAPS) and a protease inhibitor cocktail (Complete ${ }^{\mathrm{TM}}$, used according to the manufacturer's instructions, Roche Applied Science, Mannheim, Germany). Finally, a number of glass beads $(2.5 \pm 0.05-\mathrm{mm}$ diameter, Wolf Glaskugeln $\mathrm{GmbH}$, Mainz, Germany) equivalent to 0.034 times the sample weight were added to the mixture and sonification was performed twelve times $\left(15 \mathrm{sec}\right.$ each) in a water bath at $0^{\circ} \mathrm{C}$. The resulting homogenate was stirred for $30 \mathrm{~min}$ at $4^{\circ} \mathrm{C}$ in the presence of 0.025 parts (v/v) DNase (Merck, Darmstadt, Germany). Subsequently, $6.5 \mathrm{~mol} / \mathrm{l}$ urea and $2 \mathrm{~mol} / \mathrm{l}$ thiourea were added to the sample. After dissolving, 0.01 parts (v/w) $70 \mathrm{mM}$ DTT and 0.01 parts (v/w) ampholyte mixture (Servalyte 2-4, Serva, Heidelberg, Germany) were added and the homogenates were stirred for another $30 \mathrm{~min}$ at room temperature. The samples were stored at $-80^{\circ} \mathrm{C}$ or analyzed immediately.

Large-gel two-dimensional electrophoresis and evaluation of protein patterns. Proteins were separated by large-gel two- dimensional electrophoresis (2DE) as described previously $(13,14)$. The gel format was $40 \mathrm{~cm}$ (isoelectric focusing) $\mathrm{x}$ $30 \mathrm{~cm} \times 0.75 \mathrm{~mm}$ (SDS-PAGE). Capillary tube gels for isoelectric focussing were prepared with a special mixture of carrier ampholytes covering a pH range of 3.5 to 9.5. Protein (90 $\mu \mathrm{g}$ per sample) was applied to each 2DE run. Visualization of protein spots was achieved using a highly sensitive silver staining procedure (13). Protein patterns were evaluated visually on a light box (Biotec-Fischer, Reiskirchen, Germany) and quantified digitally using the Proteomweaver imaging software (version 2.1, Definiens, Munich, Germany). Corresponding protein spots in different 2DE-gels were compared for their spot intensity and spot position. Only clearly visible differences of protein spots consistent across all three mice of a group (either male vs. female or 14 vs. 100 weeks) were included in further evaluations. For spot quantification, spot volumes were calculated by a built-in feature of the software. Subsequently, spot information was extracted from Proteinweaver. Spot intensities were normalized by calculating the relative intensity, which was defined as percentage of the total spot volume to its parent gel. Finally, data on differentially expressed proteins were subjected to statistical analysis to determine the significance of groupto-group difference (unpaired Student's t-test). Differences were considered to be statistically significant when $\mathrm{p}<0.05$. The standard error of mean (mean \pm SEM) of relative spot intensities is reported.

Protein identification using mass spectrometry. Mouse heart protein $(300 \mu \mathrm{g})$ was used for protein identification as described previously (15). Briefly, proteins were electro-separated by 2DE and visualized using mass spectrometry-compatible silver staining (16). Protein spots of interest were excised from the 2DE-gel and in-gel trypsin digestion was performed. Tryptic fragments were analyzed either by Matrix-assisted laser desorption ionization-Time of flight mass spectrometry (MALDI-TOF, Bruker Reflex IV, Bruker, Bremen, Germany) or ESI-MS/MS (Deca XP ion trap MS, Thermo Electron Corporation, Karlsruhe, Germany). The mass spectra were analyzed using Mascot (www.matrixscience.com) or Sequest (version 3.1, www.field.scripps.edu/sequest). For peptide mass fingerprinting (NCBInr, mammalian species, www.ncbi. nlm.nih.gov/), the following stringent criteria were applied: Probability based Mowse Score $>36(\mathrm{p}<0.05)$ for ESI-MS/MS; Mowse scores $>61(\mathrm{p}<0.05)$, with at least three matched peptides and sequence coverage of $\geq 30 \%$ for MALDI-TOF MS.

Western blot analyses. Western blot analyses were performed to validate the differential expression of proteins that were detected by 2D-electrophoresis technique, as well as to map the observations obtained in the mouse model on human heart tissue. For this purpose, equal amounts $(20 \mu \mathrm{g})$ of protein extract were electro-separated with a $15 \%$ SDS-PAGE and transferred to a PVDF-membrane (Millipore, Bedford, MA, USA) using the Trans-Blot ${ }^{\circledR}$ SD semi-dry electrophoretic transfer cell (100 mA, 150 min, Bio-Rad, München, Germany). The membranes were subsequently blocked overnight at $4^{\circ} \mathrm{C}$ with 5\% skim dry milk solution in TBST buffer (containing $0.1 \%$ Tween-20) under mild agitation. The following seven 
Table I. Proteins that were differently expressed in female and male mouse heart tissue at two distinct ages.

\begin{tabular}{|c|c|c|}
\hline & $\begin{array}{l}\text { Young female vs. } \\
\text { young male } \\
\text { (14 weeks old) }\end{array}$ & $\begin{array}{l}\text { Old female vs. } \\
\text { old male } \\
\text { (100 weeks old) }\end{array}$ \\
\hline $\begin{array}{l}\text { Up-regulated } \\
\text { in males }\end{array}$ & $\begin{array}{l}\alpha 1 \text {-antitrypsin } \\
\text { (3 isoforms) } \\
1 \text { protein spot } \\
\text { (not identified) }\end{array}$ & $\begin{array}{c}\text { a1-antitrypsin (3 isoforms) } \\
\text { Apolipoprotein J (3 isoforms) } \\
\text { Apolipoprotein A4 (3 isoforms) } \\
\text { Apolipoprotein E } \\
\text { Apolipoprotein A2 (2 isoforms) }\end{array}$ \\
\hline $\begin{array}{l}\text { Down-regulated } \\
\text { in males }\end{array}$ & $\begin{array}{c}\text { Peroxiredoxin } 2 \\
\text { Desmin } \\
\text { Nitrilase } 1\end{array}$ & $\begin{array}{c}\text { Peroxiredoxin } 2 \\
\text { P-RhoGDI } 1 \text { ( } 2 \text { isoforms) } \\
\text { Carbonic anhydrase (6 isoforms) } \\
1 \text { protein (not identified) }\end{array}$ \\
\hline Total & $\begin{array}{c}7 \text { proteins including } \\
\text { isoforms }\end{array}$ & 22 proteins including isoforms \\
\hline
\end{tabular}

antibodies were employed to analyze both mouse and human samples: rabbit anti-human peroxiredoxin 2 (1:400, Lab Frontier, Fukushima, Japan), rabbit anti-human carbonic anhydrase 2 (1:200, Santa Cruz, Heidelberg, Germany), rabbit anti-mouse apolipoprotein E (1:400, Biozol, Eching, Germany), monoclonal mouse anti-human apolipoprotein J (1:400, Biozol, Eching, Germany), rabbit anti-human p-RhoGDI (1:200, Santa Cruz), chicken anti-human $\alpha 1$-antitrypsin $(1: 400$, Biozol) and monoclonal mouse anti-human desmin (1:200, Santa Cruz). All these antibodies have been proven to react adequately against antigens of both mouse and human origin. For chemical luminescence protein detection (ECL Western blotting detection system, GE healthcare, Solingen, Germany), appropriate horseradish peroxidase-conjugated secondary antibodies were applied. These included goat anti-rabbit IgG (1:10000, GE healthcare), sheep anti-mouse IgG (1:10000,
GE healthcare) and rabbit anti-chicken IgG (1:1000, Dianova, Hamburg, Germany). Three repeats were carried out for each Western blot experiment. For carbonic anhydrase 2, Western blot analysis was additionally carried out on 2DE gels to investigate differences in protein isoforms. Relative protein expression data were obtained through the quantification of protein band intensities (ImageQuant TL, GE healthcare).

\section{Results}

The heart proteome of female and male C57BL/6 mice of two distinct age groups (14 and 100 weeks) was analyzed by large-gel two-dimensional electrophoresis to detect differently expressed proteins between mice of different age and/or gender. Highly reproducible protein patterns were achieved by using protocols standardized in all details in our laboratory. In the silver-stained 2DE patterns of mouse heart, we detected over 3100 protein spots by visual evaluation. Approximately 3800 spots were detected reproducibly using imaging software (Proteomweaver). The comparison of mouse heart 2DE patterns of young females vs. young males revealed seven differentially expressed protein spots. Among them, four protein spots were increased and three decreased in their expression in males compared to females (Table I). Out of these seven protein spots, six were identified and found to be four distinct proteins. In old mice, 22 protein spots showed sex-dependent expression (Table I). Regarding females, twelve protein spots were increased and ten decreased in their expression level in the comparison with males. Out of these 22 protein spots, 21 were identified and found to be eight different proteins (Table I). The expression ratios of these variant proteins (male vs. female) are summarized in Table II and Fig. 3. Two distinct proteins showed sex-specific alteration in young as well as in old mice ( $\alpha 1$-antitrypsin and peroxiredoxin 2). In the following, mouse heart protein expression changes are described in groups according to their expression behavior at different ages.

Table II. An overview of age- and gender-specific proteins in heart tissues of C57BL/6 mice.

\begin{tabular}{|c|c|c|c|c|c|c|c|c|c|c|}
\hline \multirow[t]{2}{*}{ Protein } & \multirow{2}{*}{$\begin{array}{l}\text { Number of } \\
\text { isoforms }\end{array}$} & \multirow{2}{*}{$\begin{array}{c}\text { Gene bank } \\
\text { ID }\end{array}$} & \multirow{2}{*}{$\begin{array}{c}\text { Molecular } \\
\text { weight }(\mathrm{kD})\end{array}$} & \multirow[t]{2}{*}{$\mathrm{pI}$} & \multirow{2}{*}{$\begin{array}{c}\text { Mowse } \\
\text { score }\end{array}$} & \multirow{2}{*}{$\begin{array}{c}\text { Number of } \\
\text { matched peptides }\end{array}$} & \multicolumn{4}{|c|}{ Protein expression level ${ }^{a}$} \\
\hline & & & & & & & 14W Male & 14W Female & 100W Male & 100W Female \\
\hline Desmin & 1 & 1352241 & 53 & 5.21 & 380 & 44 & $1.047 \pm 0.062$ & $1.832 \pm 0.089$ & $1.069 \pm 0.086$ & $1.089 \pm 0.045$ \\
\hline Nitrilase 1 & 1 & 18204913 & 36 & 8.21 & 132 & 17 & ND & $0.612 \pm 0.081$ & $0.324 \pm 0.074$ & $0.345 \pm 0.078$ \\
\hline P-RhoGDI 1 & 2 & 31982030 & 23 & 4.6 & 143 & 16 & $1.193 \pm 0.033$ & $1.114 \pm 0.087$ & $0.94 \pm 0.039$ & $1.238 \pm 0.040$ \\
\hline Apolipoprotein $\mathrm{J}$ & 3 & 729152 & 52 & 5.12 & 280 & 5 & ND & ND & $0.47 \pm 0.151$ & ND \\
\hline Apolipoprotein A2 & 2 & 109574 & 11 & 5.2 & 213 & 4 & ND & ND & $1.514 \pm 0.337$ & ND \\
\hline Apolipoprotein E & 1 & 114041 & 36 & 5.19 & 507 & 10 & ND & ND & $0.712 \pm 0.029$ & ND \\
\hline Apolipoprotein A4 & 3 & 191885 & 45 & 6.5 & 275 & 27 & $0.143 \pm 0.032$ & $0.162 \pm 0.034$ & $1.246 \pm 0.371$ & $0.575 \pm 0.074$ \\
\hline$\alpha 1$-antitrypsin & 3 & $\begin{array}{c}1703024(1-1) \\
15012149(1-3) ; \\
3023213(1-5)\end{array}$ & 61 & 4.7 & 521 & 8 & $0.805 \pm 0.169$ & $0.232 \pm 0.047$ & $0.611 \pm 0.085$ & ND \\
\hline Peroxiredoxin 2 & 1 & 51980699 & 21 & 4 & 144 & 14 & $1.027 \pm 0.064$ & $1.436 \pm 0.080$ & $1.199 \pm 0.001$ & $1.808 \pm 0.085$ \\
\hline
\end{tabular}

${ }^{a}$ Values of protein expression level account for percent intensity of protein spots on the 2DE patterns. ND, not detected; 14W, 14-week-old; 100W, 100-week-old; pI, isoelectric point. 

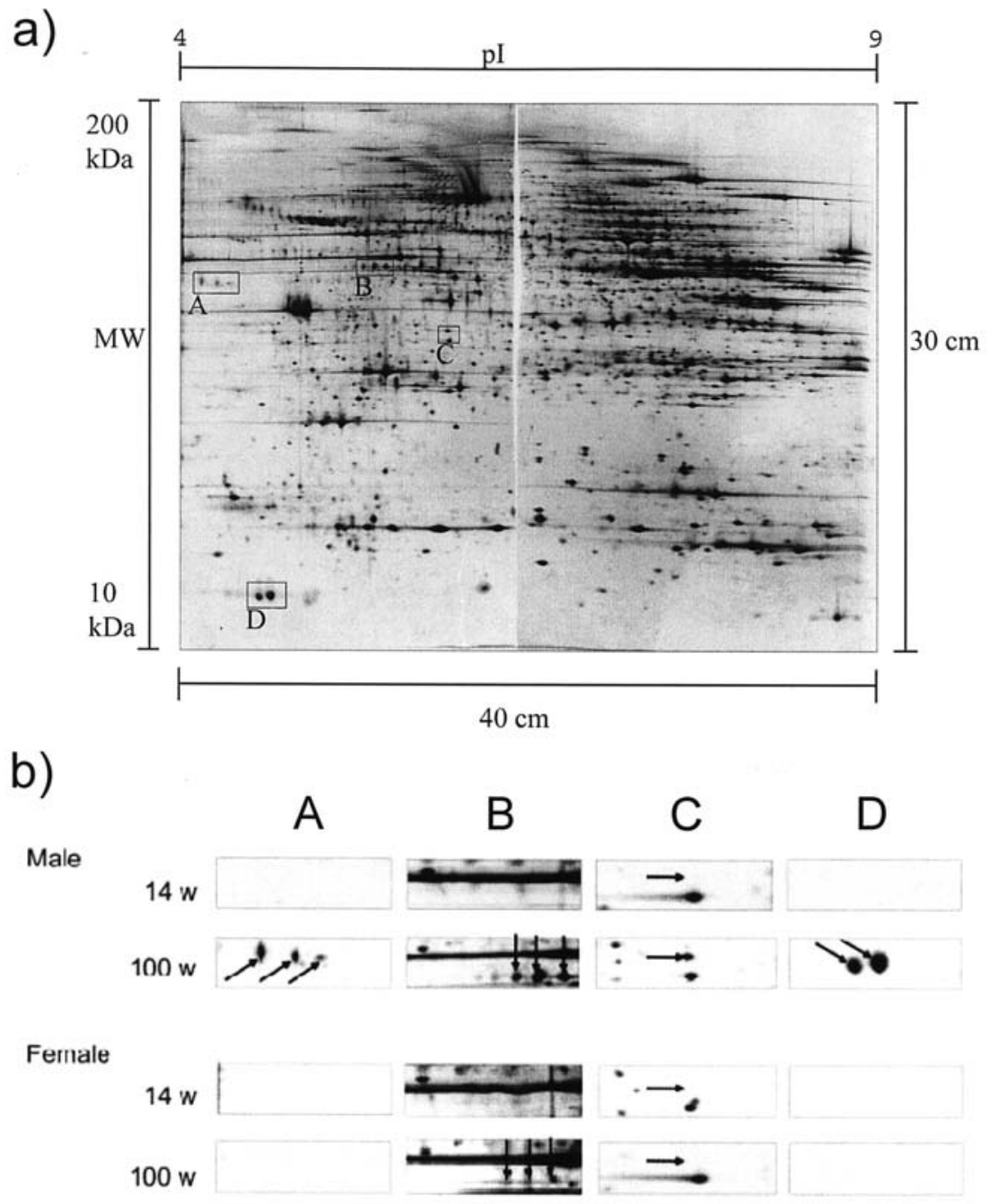

Figure 1. Large-gel two-dimensional electrophoresis of the mouse heart proteome. (a) Representative silver-stained 2DE pattern of the heart proteome (male C57BL/6 mouse, 100 weeks). pI, isoelectric point. (b) Nine protein spots (arrows), which represent four different apolipoproteins, showed a gender-specific expression profile in heart tissue of 100-week-old mice. (A) Apolipoprotein $\mathbf{J}$ (three isoforms); (B) apolipoprotein A4 (three isoforms); (C) apolipoprotein E; and (D) apolipoprotein A2 (two isoforms).

Proteins with highest expression in young female mice. Two proteins demonstrated their highest expression level in the 14-week-old female animals (Table II): desmin (GI: 1352241) and nitrilase 1 (GI: 18204913). Expression of desmin was also comparably low in young males, old males and old females (Fig. 3a). Nitrilase 1 showed only medium expression in old female and old male animals. The corresponding spot of this protein was not detectable in 2DE patterns of young males (Fig. 3b).

Proteins with highest expression in old female mice. Rho GDP dissociation inhibitor $\alpha$ (P-RhoGDI 1, GI: 31982030) was characterized by its highest expression level in old females and lowest expression in old males. Medium expression of this protein was observed in young male and female animals (Fig. 3c). Furthermore, a series of six protein spots which were identified as carbonic anhydrase 2 (CA2, GI: 31981657) was only present in protein patterns of old female hearts, but was below the detection limit in males or young females.

Proteins with highest expression in old male mice. A third group of proteins exhibited their highest expression in old male hearts. Apolipoprotein J (ApoJ, GI: 729152) was present only in the old males. This protein was located in the acidic region of the $2 \mathrm{DE}$ pattern as a group of three protein spots differing in isoelectric point (pI) and molecular weight (Fig. 1bA). Likewise, apolipoprotein A2 (ApoA2, GI: 109574) and apolipoprotein E (ApoE, GI: 114041) were visible exclusively in the aged males. ApoA2 was identified as a twin spot in the lower molecular weight region of the $2 \mathrm{DE}$ patterns (Fig. 1bD). ApoE presented as a single spot in the central region of the 2DE-gels (Fig. 1bC). Moreover, a series of three parallel spots identified as apolipoprotein A4 (ApoA4, GI: 191885, Fig. 1bB) exhibited their highest expression in old males, lower expression in old females and lowest expression in young animals of both sexes (Fig. 3d).

Proteins that showed expression differences between young and old animals in both genders. The expression levels of three additional protein spots were up-regulated in young and old males compared to females of the respective age group, with stronger sex-related differences in aged animals. At 100 weeks of age, the three spots were down-regulated below the detection limit in old female mouse hearts (Fig. 3e). These three 
Male

a) 1

$14 \mathrm{w}$
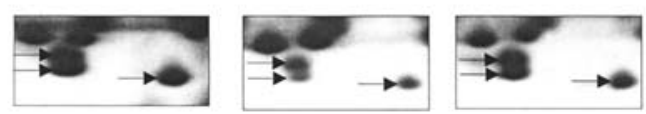

$100 w$
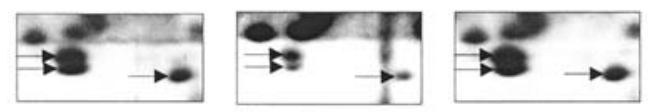

Female

b) 1

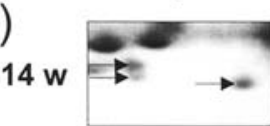

$100 \mathrm{w}$
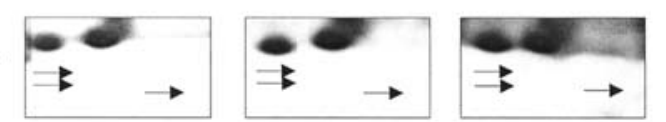

Figure 2. Sections of 2DE heart protein patterns showing the appearance of three protein spots (arrows) in young (14-week-old, $14 \mathrm{w}$ ) and old (100week-old, $100 \mathrm{w}$ ) mice of both genders. (a) The permanence of the three spots in young and old male mice. (b) The appearance of the three spots shown in a, but here in female mice. All three protein spots appeared in young females with lower intensities than in young males. These spots disappeared in old females completely. The double spot was identified by mass spectrometry to be a protein mixture of $\alpha 1$-antitrypsin 1-1 and 1-5. The single spot was $\alpha 1$-antitrypsin 1-3. spots present as a pair of double spots that differ predominantly in molecular weight (Fig. 2, left arrows of each gel section) and in having a single spot shifted to the more basic side of them (Fig. 2, right arrow of each gel section). The analysis with mass spectrometry led to the identification of the double spots (Fig. 2, left arrows) as a mixture of $\alpha 1$-antitrypsin (AAT) isoform 1-1 (GI: 1703024) and $\alpha 1$-antitrypsin isoform 1-5 (GI: 3023213). The single spot at the right side was identified as a further isoform of the same protein, termed $\alpha 1$-antitrypsin 1-3 (GI: 1501249). In addition, a further protein spot identified as peroxiredoxin $2(\operatorname{Prdx} 2, \mathrm{GI}: 51980699)$ had a higher expression level in female mice than in males of both age groups. Again, the gender difference was more pronounced in the aged animals (Fig. 3f).

Comparison of 2DE pattern between mouse and human heart. In an attempt to investigate the protein spots that revealed sex-specific expression in the mouse heart also in human heart, biopsies from six women and six men of similar ages (between 50 and 60 years old) were investigated by 2DE as for the mouse heart samples. The protein patterns of mouse and human heart were generally similar (Fig. 4). However, this is mainly due to very characteristic and prominent spots occurring all over the protein patterns in both mouse and human heart. Considering the details of these patterns, many protein spots appear to be unique either for mouse or human heart due to differences in spot location and appearance. As a consequence, of all the proteins found to be sex-specifically expressed in the mouse, only $\alpha 1$-antitrypsin could be projected to human heart protein patterns based on visual protein pattern comparison (Fig. 4). In the human heart 2DE pattern, a)
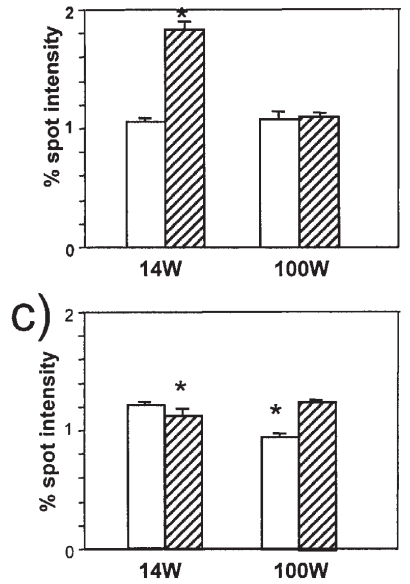

e)

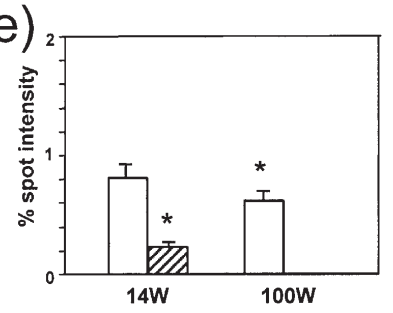

b)
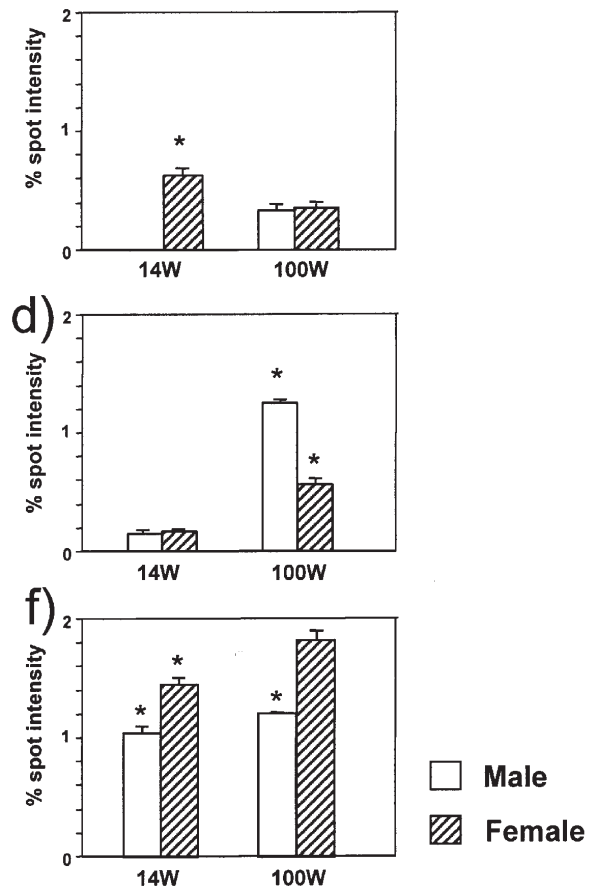

Figure 3. Bar charts showing expression profiles of murine heart proteins with sex-dependent differences in the two age groups, represented by spot intensity data (means \pm SEM). Each bar denotes a grouping of three mice of the same age and sex. In each diagram, the group(s) marked with asterisks showed a significant difference compared to other groups in the same diagram (*p<0.05). (a) Desmin, (b) nitrilase 1, (c) P-RhoGDI 1, (d) ApoA4, (e) $\alpha 1$-antitrypsin and (f) peroxiredoxin $2.14 \mathrm{~W}, 14$ weeks of age; $100 \mathrm{~W}, 100$ weeks of age. 
a)
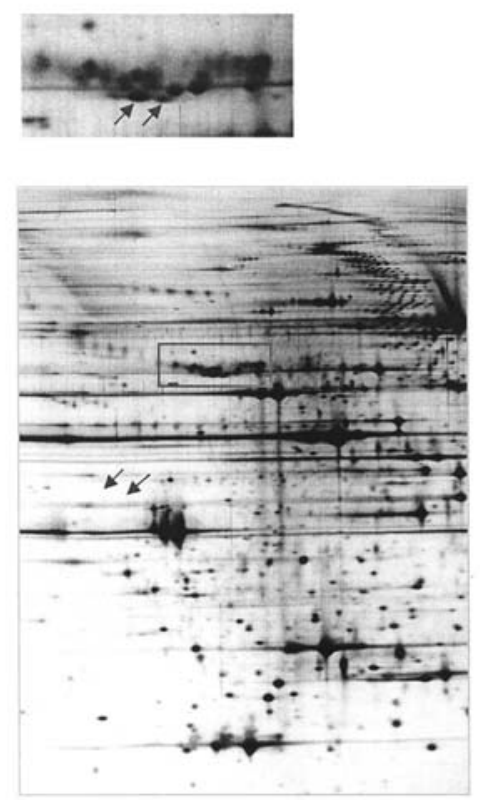

c)
Mouse b)
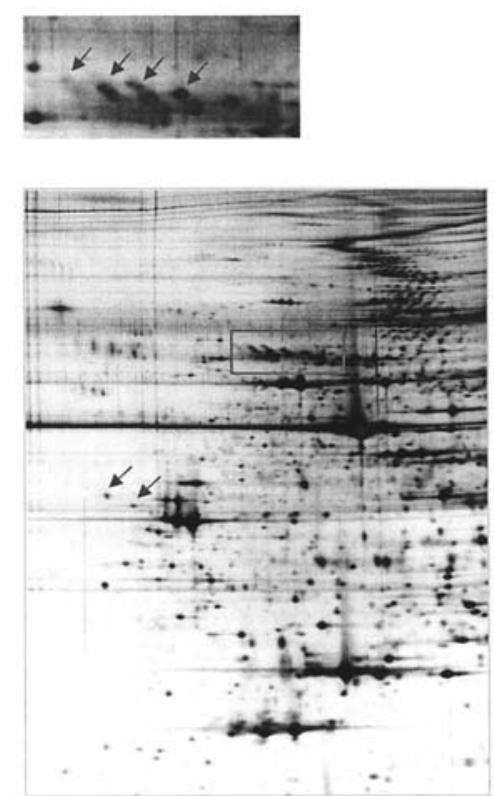

Human

Figure 4. Comparison of 2DE protein patterns of mouse and human heart. 2DE heart protein patterns from mouse and human (male) can be correlated, to a certain extent, quite well due to characteristic spots and groups of spots which can be recognized immediately in both patterns. This allowed us to detect the sex-specific mouse $\alpha 1$-antitrypsin spots (a, arrows) also in the human pattern (b). However, the two isoforms of $\alpha 1$-antitrypsin fragments detected in the human pattern coincidentally by mass spectrometry in a lower region ( $d$, arrows) were not present at that position in the mouse (c).

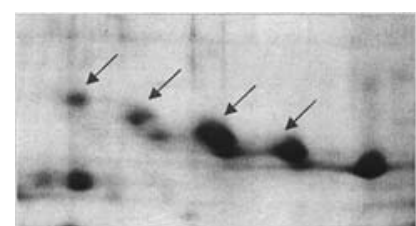

a)

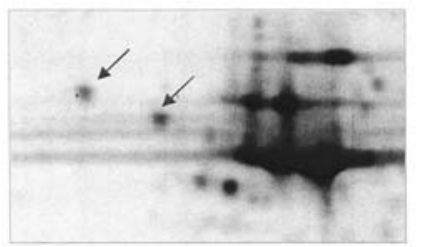

c)

Male

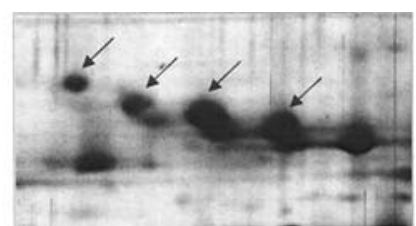

b)

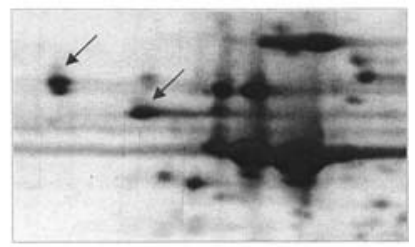

d)

\section{Female}

Figure 5. Protein spots of $\alpha 1$-antitrypsin in human male and female heart $2 \mathrm{DE}$ patterns. A chain of protein spots representing human $\alpha 1$-antitrypsin was detected in the upper part of the protein pattern ( $a$ and $b$ ). Two additional spots in the lower part of the 2DE-gel presumably represent fragments of human $\alpha 1$-antitrypsin (c and d). Gender-specific differences were quite obvious for spots shown in $\mathrm{c}$ and $\mathrm{d}$ but less pronounced for the spots shown in $\mathrm{a}$ and $\mathrm{b}$.

$\alpha 1$-antitrypsin occurred as a chain of four spots bearing slight modifications in isoelectric point and molecular weight. In addition to this spot chain, two protein spots in a far lower molecular weight area of human heart 2DE patterns were

also identified as human $\alpha 1$-antitrypsin (Fig. 4). The $\alpha 1$ antitrypsin spots found in the mouse 2DE pattern clearly correlate in position with the upper group of spots rather than with the lower spots of the human $\alpha 1$-antitrypsin. With regard to sex specificity, this protein showed opposite behavior in mouse and human heart. In mouse heart, it was drastically increased in males, but in human heart these protein spots showed higher expression levels in women (four out of six cases). This was also true for the two additional isoforms of antitrypsin in the lower molecular weight area (five out of six cases) (Fig. 5).

Western blot analyses on mouse and human samples. Immunoblots of four proteins of mouse heart confirmed our findings obtained by 2DE pattern analysis: compared to old females, old males had down-regulated peroxiredoxin 2 and carbonic anhydrase 2 but up-regulated ApoE and ApoJ (Fig. 6a). The decreased expression of carbonic anhydrase 2 in the old male mouse was additionally confirmed using Western immunoblotting on the 2DE-gel, where this protein was resolved into 4 protein isoforms. All of them were downregulated in old males (Fig. 6d). Expression levels of the other three proteins (p-RhoGDI 1, desmin and $\alpha 1$-antitrypsin) showed no significant differences between males and females by Western blot analysis, reflecting the lower sensitivity of immunoblotting technique compared to $2 \mathrm{DE}$ in discriminating differences in protein levels.

As all antibodies chosen in this study were proven to react against both mouse and human antigens (see Materials and methods for details), we employed the same pallet of 
a)

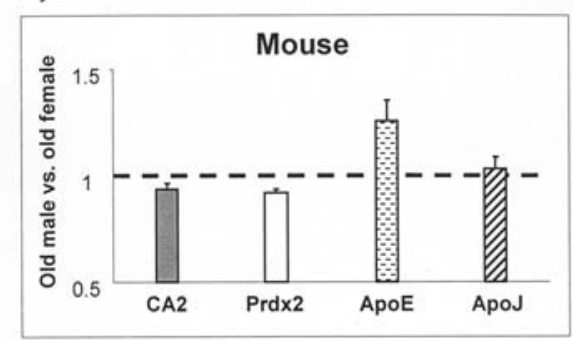

c)

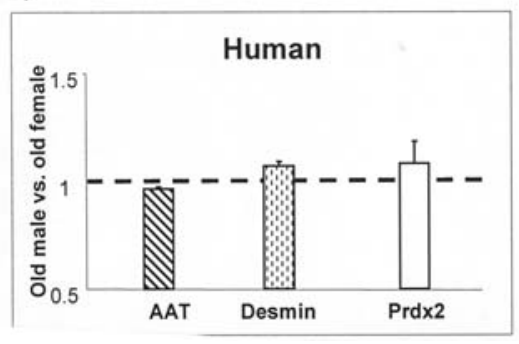

b)

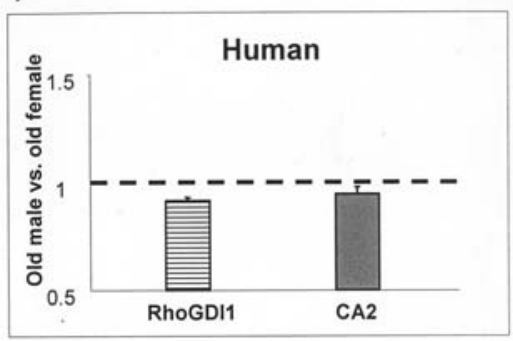

d)

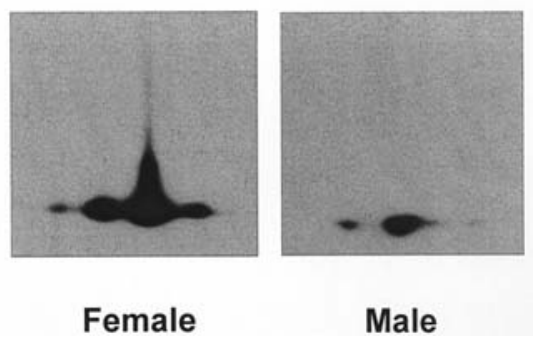

Figure 6. Gender-dependent protein expression ratios (male vs. female) in human and mouse heart tissue, as revealed by Western immunoblotting analyses. (a) Gender-specific expression patterns of CA2, Prdx2, ApoE and ApoJ observed in the mouse heart 2DE pattern were validated by Western blot analysis. (b) Gender-dependent protein expression of P-RhoGDI 1 and CA2 was similar in both human and mouse. (c) Three proteins (AAT, desmin and Prdx2) showed an opposite gender-dependency in human compared to in mouse heart. (d) Gender dependency of mouse carbonic anhydrase 2 was additionally confirmed by Western blot analysis on 2DE-gels. The expression levels of 4 isoforms of carbonic anhydrase 2 in 100 -week-old female mouse heart were $>1.7$ times the expression levels in male mice of the same age.

antibodies used to test the mouse proteins also for the human heart samples. Consistent to our finding in mouse heart, carbonic anhydrase 2 and p-RhoGDI 1 showed sex specificity in human heart as well (down-regulation in men, Fig. 6b). As shown in Fig. 6c, desmin, Prdx 2 and $\alpha 1$-antitrypsin also showed sex specificity in human heart, albeit in the opposite direction to that in mouse heart (desmin and $\operatorname{Prdx} 2$ were upregulated in men, $\alpha 1$-antitrypsin was down-regulated in men). The expression level of the other two proteins (ApoE and ApoJ) did not show significant differences between male and female human heart tissue.

\section{Discussion}

The goal of the current study was to characterize the influence of sex and age on heart protein expression. Due to the scarcity of human tissue samples, we first employed C57BL/6 mice, a standard mouse strain that has been proven to be a pertinent model for studying human heart diseases $(17,18)$. The use of well-characterized inbred mouse strains reduces the possible influences of genetic polymorphisms on protein expression patterns, a problem involved in investigations of human individuals. Our 2DE analysis of heart tissues of 14- and 100 -week-old mice of both genders resulted in the detection of over 20 protein spots with sex-specific expression profiles depending to some extent on age. These protein spots were identified by mass spectrometry as ten distinct proteins. Findings based on 2DE were confirmed in most cases by immunoblotting.

Taking into account that approximately 3800 proteins (including isoforms) were evaluated at two ages, the effect of sex specificity on protein expression in the heart seems to be rather small $(0.18 \%$ of proteins in the young stage and $0.58 \%$ in the old stage). This notion gains even more prominence when it is considered that four of the proteins bearing age/ gender-specific expression profiles belong to the same protein family (apolipoproteins). This could imply that gender effects manifest predominantly via a more subtle protein interaction network, rather than by distinct protein reactions. As another general observation, a larger number of proteins showed sex differences in old heart tissues than in young tissues. The variant proteins found in the two age groups overlapped in only two distinct proteins. Apparently, the extent of sexspecific protein expression depends considerably on age. Therefore, age should be considered as an important factor when studying gender effects in heart diseases.

Age-independent peroxiredoxin up-regulation in female mice suggests a better redox-defence in females. In this study, we observed that peroxiredoxin 2 expression clearly shows sex specificity. The expression level of peroxiredoxin 2 was higher in female than in male mouse hearts, independently of age. Antioxidative capacity is an important protective mechanism in cardiovascular diseases, particularly in atherosclerosis (11), which is much more frequent in men than in women until approximately 70 years old (19-27). Specifically, peroxiredoxin 2 is a negative regulator of platelet-driven growth factor (PDGF) signalling. Peroxiredoxin 2 deficiency can result in increased $\mathrm{H}_{2} \mathrm{O}_{2}$ production, enhanced activation of PDGF receptor, and subsequently increased cell proliferation and migration in the vascular remodelling process (28). The underrepresentation of peroxiredoxin 2 in males suggests a lower redox regulation capacity in males. The more pronounced early differences in peroxiredoxin 2 expression may be due to 
additional protective mechanisms contributed by sex hormones in young females (29).

Over-representation of oxidized apolipoproteins in aged male heart reflects a greater susceptibility of aged males to oxidative stress. Comparisons of $2 \mathrm{DE}$ protein patterns of aged female and aged male mice revealed sex specificities of four different apolipoproteins (ApoJ, ApoA4, ApoE and ApoA2). Consistent results were also supplied by Western blot analyses (in mouse, but not in human heart). All of these apolipoproteins occurred preferentially in aged male, rather than female, mouse hearts. Interestingly, three of these apolipoproteins occurred as groups of spots differing in isoelectric points on the $2 \mathrm{DE}$ protein pattern. This could indicate posttranslational modification of these apolipoproteins, for instance by protein oxidation. Under heightened oxidative stress, the methionine residues of apolipoproteins can be consecutively oxidized to their respective methionine sulfoxide (30). Such oxidation would give extra negative charges to the protein, which result in isoforms bearing a characteristic spot chain appearance. Several lines of evidence suggest that there is an increase in the level of reactive oxygen species (ROS) with aging (31-33). According to our observation of a higher level of peroxiredoxin in females, the male organism is more susceptible to ROS in old age than the female organism. This is in line with previous findings that the level of lipid oxidation is higher in aged males than females (34-36). A relation between lipoprotein oxidation and atherosclerosis has been described previously $(37,38)$. Atherosclerosis is characterized by the accumulation of both lipoprotein-derived lipids and inflammatory cells in the affected vascular wall $(30,39,40)$. The oxidation of lipoproteins is an important contributor to atherosclerosis and coronary heart disease, since oxidized lipoproteins can cause serious damage of the vascular wall $(38,41,42)$. The more advanced apolipoprotein oxidation in old males is in accordance with the fact that atherosclerosis affects men more severely than women (29).

Desmin and nitrilase 1 were up-regulated in female mice in young adulthood. Another two proteins (desmin and nitrilase 1) showed higher expression in young female hearts, while no difference was observed in aged animals. Nitrilase 1 could be involved in hormone metabolism (43). The pathophysiological role of this protein is still unknown. Desmin is a cytoskeletal protein of high abundance in cardiomyocytes (44). Recent evidence suggests that desmin could play an important role in regulating myogenesis (45). Indeed, a rare desmin-linked cardiomyopathy exists in humans (46).

A higher level of p-RhoGDI 1 and carbonic anhydrase in old females could be connected to age-related estrogen loss. Two other proteins, p-RhoGDI 1 and carbonic anhydrase 2 (CA2) showed increased expression profiles in aged female human and murine hearts. P-RhoGDI 1 acts as an inhibitor of the Rho family small $\mathrm{G}$ proteins by preventing a return to their ligand-dependent active form $(47,48)$. RhoGDI 1 is involved in pathological cardiac hypertrophy $(49,50)$. Recently, Laufs et al described the suppression of small $\mathrm{G}$ protein rac-1 at the transcriptional level by estrogen (51). An increased expression of p-RhoGDI 1 in the old female heart reflects the increased expression level of rac-1 due to the estrogen loss during aging. This, in turn, could interfere with the signalling pathway in myocardial hypertrophy.

As a key enzyme responsible for osteoclastic bone resorption, CA2 and its up-regulation in bone tissue have been intensively studied in postmenopausal or ovariectomized animal models $(52,53)$. The similar behavior of this protein in the heart of aged females could be attributed to estrogen deficiency. Recently, Alvarez and colleagues suggested a novel role of carbonic anhydrase in mediating the hypertrophic response of cardiac myocytes through stimulating the transport flux of plasma membrane ion exchangers (54). The increase of CA2 expression in old females could correlate to the gradual loss of this protective mechanism that has been preventing cardiomyocyte hypertrophy during the young female life phase.

The expression pattern of al-antitrypsin resembles sex hormone levels. In the present study, we found that $\alpha 1$ antitrypsin 1-1, 1-3, and 1-5 showed both age- and sex-specific expression profiles in the heart tissue of mice. Compared to males, the cardiac protein levels of all three isoforms of $\alpha 1$ antitrypsin were lower in the expression profiles of young females. At 100 weeks, these protein spots disappeared completely in the female heart protein pattern, whereas they were still present in male 2DE patterns. $\alpha 1$-antitrypsin, a serine proteinase inhibitor (55), is associated with diverse biological processes including age-dependent processes such as renal and sperm development, and sex-dependent processes such as hormone transport and homeostasis (56). Higher expression of $\alpha 1$-antitrypsin in males than in females has already been observed in mouse brain (57). Previous studies have shown that the $\alpha 1$-antitrypsin 1-5 level is directly correlated with the testosterone level $(58,59)$ and can be inhibited by the administration of estrogen (60). Therefore, the sex- and age-related expression of $\alpha 1$-antitrypsin detected in our protein patterns is in line with several observations that have been reported. Unlike humans, who have a single gene for $\alpha 1$-antitrypsin, Mus domesticus possess multiple copies of this gene (61). The occurrence of different $\alpha 1$ antitrypsin isoforms in the mouse and human protein patterns may explain their different sex-related behavior. Furthermore, our observation on this protein may be taken as a hint that sex- and age-specific expression of proteins could in certain cases be a matter of protein isoforms rather than of the total protein.

The relevance of the observation made in the mouse model to humans. In order to explore to what extent age- and sexspecific heart protein expression found in the mouse can be applied to humans, we first compared the 2DE patterns of mouse and human hearts and then used antibodies to investigate the sex-related proteins found in mice also in humans. Of all the seven proteins investigated in human tissues samples, only two (CA2 and p-RhoGDI 1) showed consistent behavior in humans and mice, whereas three further proteins showed the opposite expression pattern (Prdx2, AAT and desmin). These results show the problem that may occur when mouse results are translated to humans.

In conclusion, our investigation allowed us to detect ten proteins with age- and sex-specific expression profiles in 
mouse heart tissue. Two of these proteins showed the same expression behavior in men. Although these protein expression differences were found in healthy organisms, some of them are known to be involved in the pathomechanisms of cardiovascular disease. This suggests that the effect of age and sex on protein expression may play an essential role in the development of clinical phenotypes of cardiovascular disease.

\section{Acknowledgements}

This study was carried out in the frame of the Graduate School Project 754 'Myocardial gene expression and the function of myocardial hypertrophy' supported by the German Research Foundation (DFG). In addition, this study was supported by the German Ministry for Education and Research (BMBF) within the German National Genome Research Network (NGFN) and by the EU Eugeneheart project (018833). We would like to thank Janine Stuwe for her help with the Western blot analyses and Anne Gale for her editorial assistance.

\section{References}

1. Lakatta EG: Age-associated cardiovascular changes in health: impact on cardiovascular disease in older persons. Heart Fail Rev 7: 29-49, 2002.

2. Simkhovich BZ, Marjoram P, Poizat C, Kedes L and Kloner RA: Age-related changes of cardiac gene expression following myocardial ischemia/reperfusion. Arch Biochem Biophys 420: 268-278, 2003.

3. Ho JE, Paultre F and Mosca L: The gender gap in coronary heart disease mortality: is there a difference between blacks and whites? J Womens Health 14: 117-127, 2005.

4. Regitz-Zagrosek V: Therapeutic implications of the genderspecific aspects of cardiovascular disease. Nat Rev Drug Discov 5: 425-438, 2006

5. de Simone G, Devereux RB, Daniels SR and Meyer RA: Gender differences in left ventricular growth. Hypertension 26: 979-983, 1995.

6. Oxenham $\mathrm{H}$ and Sharpe N: Cardiovascular aging and heart failure. Eur J Heart Fail 5: 427-434, 2003.

7. Anversa P, Palackal T, Sonnenblick EH, Olivetti G, Meggs LG and Capasso JM: Myocyte cell loss and myocyte cellular hyperplasia in the hypertrophied aging rat heart. Circ Res 67: 871-885, 1990.

8. Olivetti G, Melissari M, Capasso JM and Anversa P: Cardiomyopathy of the aging human heart. Myocyte loss and reactive cellular hypertrophy. Circ Res 68: 1560-1568, 1991.

9. Carroll JD, Carroll EP, Feldman T, Ward DM, Lang RM, McGaughey D and Karp RB: Sex-associated differences in left ventricular function in aortic stenosis of the elderly. Circulation 86: 1099-1107, 1992.

10. Jiang L, Tsubakihara M, Heinke MY, Yao M, Dunn MJ, Phillips W, dos Remedios CG and Nosworthy NJ: Heart failure and apoptosis: electrophoretic methods support data from microand macro-arrays. A critical review of genomics and proteomics. Proteomics 1: 1481-1488, 2001.

11. Cullingford TE, Wait R, Clerk A and Sugden PH: Effects of oxidative stress on the cardiac myocyte proteome: modifications to peroxiredoxins and small heat shock proteins. J Mol Cell Cardiol 40: 157-172, 2006.

12. McGregor E and Dunn MJ: Proteomics of the heart: unraveling disease. Circ Res 98: 309-321, 2006.

13. Klose J and Kobalz U: Two-dimensional electrophoresis of proteins: an updated protocol and implications for a functional analysis of the genome. Electrophoresis 16: 1034-1059, 1995.

14. Klose J: Large-gel 2-D electrophoresis. Methods Mol Biol 112: $147-172,1999$

15. Zabel C, Sagi D, Kaindl AM, Steireif N, Klare Y, Mao L, Peters H, Wacker MA, Kleene R and Klose J: Comparative proteomics in neurodegenerative and non-neurodegenerative diseases suggest nodal point proteins in regulatory networking. $\mathrm{J}$ Proteome Res 5: 1948-1958, 2006.
16. Nebrich G, Herrmann M, Sagi D, Klose J and Giavalisco P: High MS-compatibility of silver nitrate-stained protein spots from 2-DE gels using ZipPlates and AnchorChips for successful protein identification. Electrophoresis 28: 1607-1614, 2007.

17. Squires CE, Escobar GP, Payne JF, Leonardi RA, Goshorn DK, Sheats NJ, Mains IM, Mingoia JT, Flack EC and Lindsey ML: Altered fibroblast function following myocardial infarction. $\mathrm{J}$ Mol Cell Cardiol 39: 699-707, 2005

18. Hemdahl AL, Caligiuri G, Hansson GK and Thoren P: Electrocardiographic characterization of stress-induced myocardial infarction in atherosclerotic mice. Acta Physiol Scand 184: 87-94, 2005.

19. Dubey RK, Oparil S, Imthurn B and Jackson EK: Sex hormones and hypertension. Cardiovasc Res 53: 688-708, 2002.

20. Hayes SN and Taler SJ: Hypertension in women: current understanding of gender differences. Mayo Clin Proc 73: 157-165, 1998.

21. Lee K, Park JS, Kim YJ, Soo Lee YS, Sook Hwang TS, Kim DJ, Park EM and Park YM: Differential expression of Prx I and II in mouse testis and their up-regulation by radiation. Biochem Biophys Res Commun 296: 337-342, 2002.

22. Lowel H, Meisinger C, Heier M, Hormann A, Kuch B, Gostomzyk J and Koenig W: Sex specific trends of sudden cardiac death and acute myocardial infarction: results of the population-based KORA/MONICA-Augsburg register 1985 to 1998. Dtsch Med Wochenschr 127: 2311-2316, 2002.

23. Mendelsohn ME and Karas RH: The protective effects of estrogen on the cardiovascular system. N Engl J Med 340: 1801-1811, 1999.

24. Reckelhoff JF: Gender differences in the regulation of blood pressure. Hypertension 37: 1199-1208, 2001.

25. Regitz-Zagrosek V, Lehmkuhl E, Lehmkuhl HB and Hetzer R: Gender aspects in heart failure. Pathophysiology and medical therapy. Arch Mal Coeur Vaiss 97: 899-908, 2004.

26. Regitz-Zagrosek V, Lehmkuhl E and Weickert MO: Gender differences in the metabolic syndrome and their role for cardiovascular disease. Clin Res Cardiol 95: 136-147, 2006.

27. Wood ZA, Schroder E, Robin Harris J and Poole LB: Structure, mechanism and regulation of peroxiredoxins. Trends Biochem Sci 28: 32-40, 2003 .

28. Choi J, Rees HD, Weintraub ST, Levey AI, Chin LS and Li L: Oxidative modifications and aggregation of $\mathrm{Cu}, \mathrm{Zn}$-superoxide dismutase associated with Alzheimer and Parkinson diseases. J Biol Chem 280: 11648-11655, 2005.

29. Regitz-Zagrosek V: Therapeutic implications of the genderspecific aspects of cardiovascular disease. Nat Rev Drug Discov 5: 425-438, 2006.

30. Panzenbock U and Stocker R: Formation of methionine sulfoxidecontaining specific forms of oxidized high-density lipoproteins. Biochim Biophys Acta 1703: 171-181, 2005.

31. Halliwell B: Free radicals, antioxidants, and human disease: curiosity, cause, or consequence? Lancet 344: 721-724, 1994.

32. Ji LL: Exercise at old age: does it increase or alleviate oxidative stress? Ann NY Acad Sci 928: 236-247, 2001.

33. Finkel $\mathrm{T}$ and Holbrook NJ: Oxidants, oxidative stress and the biology of ageing. Nature 408: 239-247, 2000.

34. Toth MJ, Gardner AW, Arciero PJ, Calles-Escandon J and Poehlman ET: Gender differences in fat oxidation and sympathetic nervous system activity at rest and during submaximal exercise in older individuals. Clin Sci 95: 59-66, 1998.

35. Blaak E: Gender differences in fat metabolism. Curr Opin Clin Nutr Metab Care 4: 499-502, 2001.

36. Atshaves BP, Payne HR, McIntosh AL, Tichy SE, Russell D, Kier AB and Schroeder F: Sexually dimorphic metabolism of branched-chain lipids in C57BL/6J mice. J Lipid Res 45: 812-830, 2004.

37. Kronenberg F, Kronenberg MF, Kiechl S, Trenkwalder E, Santer P, Oberhollenzer F, Egger G, Utermann G and Willeit J: Role of lipoprotein(a) and apolipoprotein(a) phenotype in atherogenesis: prospective results from the Bruneck study. Circulation 100: 1154-1160, 1999.

38. Paultre F, Tuck CH, Boden-Albala B, Kargman DE, Todd E, Jones J, Paik MC, Sacco RL and Berglund L: Relation of Apo(a) size to carotid atherosclerosis in an elderly multiethnic population. Arterioscler Thromb Vasc Biol 22: 141-146, 2002.

39. Lusis AJ: Atherosclerosis. Nature 407: 233-241, 2000.

40. Zaman AG, Helft G, Worthley SG and Badimon JJ: The role of plaque rupture and thrombosis in coronary artery disease. Atherosclerosis 149: 251-266, 2000. 
41. Navab M, Ananthramaiah GM, Reddy ST, Van Lenten BJ, Ansell BJ, Fonarow GC, Vahabzadeh K, Hama S, Hough G, Kamranpour N, Berliner JA, Lusis AJ and Fogelman AM: The oxidation hypothesis of atherogenesis: the role of oxidized phospholipids and HDL. J Lipid Res 45: 993-1007, 2004.

42. Kronenberg F, Kuen E, Ritz E, Junker R, Konig P, Kraatz G, Lhotta K, Mann JF, Muller GA, Neyer U, Riegel W, Reigler P, Schwenger V and Von Eckardstein A: Lipoprotein(a) serum concentrations and apolipoprotein(a) phenotypes in mild and moderate renal failure. J Am Soc Nephrol 11: 105-115, 2000.

43. Bartling D, Seedorf M, Mithofer A and Weiler EW: Cloning and expression of an Arabidopsis nitrilase which can convert indole-3-acetonitrile to the plant hormone, indole-3-acetic acid. Eur J Biochem 205: 417-424, 1992.

44. Kostin S, Hein S, Arnon E, Scholz D and Schaper J: The cytoskeleton and related proteins in the human failing heart. Heart Fail Rev 5: 271-280, 2000.

45. Capetanaki Y: Desmin cytoskeleton in healthy and failing heart. Heart Fail Rev 5: 203-220, 2000.

46. Arbustini E, Pasotti M, Pilotto A, Pellegrini C, Grasso M, Previtali S, Repetto A, Bellini O, Azan G, Scaffino M, Campana C, Piccolo G, Vigano M and Tavazzi L: Desmin accumulation restrictive cardiomyopathy and atrioventricular block associated with desmin gene defects. Eur J Heart Fail 8: 477-483, 2006.

47. DerMardirossian C, Schnelzer A and Bokoch GM: Phosphorylation of RhoGDI by Pak1 mediates dissociation of Rac GTPase. Mol Cell 15: 117-127, 2004.

48. Mitsui K, Nakayama H, Akagi T, Nekooki M, Ohtawa K, Takio K, Hashikawa T and Nukina N: Purification of polyglutamine aggregates and identification of elongation factor1 alpha and heat shock protein 84 as aggregate-interacting proteins. J Neurosci 22: 9267-9277, 2002.

49. Wei L, Taffet GE, Khoury DS, Bo J, Li Y, Yatani A, Delaughter MC, Klevitsky R, Hewett TE, Robbins J, Michael LH, Schneider MD, Entman ML and Schwartz RJ: Disruption of Rho signaling results in progressive atrioventricular conduction defects while ventricular function remains preserved. FASEB J 18: 857-859, 2004

50. Aikawa R, Komuro I, Nagai R and Yazaki Y: Rho plays an important role in angiotensin II-induced hypertrophic responses in cardiac myocytes. Mol Cell Biochem 212: 177-182, 2000.
51. Laufs U, Adam O, Strehlow K, Wassmann S, Konkol C, Laufs K, Schmidt W, Bohm M and Nickenig G: Down-regulation of Rac-1 GTPase by Estrogen. J Biol Chem 278: 5956-5962, 2003.

52. Zheng MH, Lau TT, Prince R, Criddle A, Wysocki S, Beilharz M, Papadimitriou JM and Wood DJ: 17 beta-estradiol suppresses gene expression of tartrate-resistant acid phosphatase and carbonic anhydrase II in ovariectomized rats. Calcif Tissue Int 56: 166-169, 1995.

53. Huang WH, Lau AT, Daniels LL, Fujii H, Seydel U, Wood DJ, Papadimitriou JM and Zheng MH: Detection of estrogen receptor alpha, carbonic anhydrase II and tartrate-resistant acid phosphatase mRNAs in putative mononuclear osteoclast precursor cells of neonatal rats by fluorescence in situ hybridization. J Mol Endocrinol 20: 211-219, 1998.

54. Alvarez BV, Johnson DE, Sowah D, Soliman D, Light PE, Xia Y, Karmazyn M and Casey JR: Carbonic anhydrase inhibition prevents and reverts cardiomyocyte hypertrophy. J Physiol 579: $127-145,2007$.

55. Potempa J, Korzus E and Travis J: The serpin superfamily of proteinase inhibitors: structure, function, and regulation. J Biol Chem 269: 15957-15960, 1994.

56. Forsyth S, Horvath A and Coughlin P: A review and comparison of the murine alpha1-antitrypsin and alpha1-antichymotrypsin multigene clusters with the human clade A serpins. Genomics 81: 336-345, 2003.

57. Zabel C, Chamrad DC, Priller J, Woodman B, Meyer HE, Bates GP and Klose J: Alterations in the mouse and human proteome caused by Huntington's disease. Mol Cell Proteomics 1: 366-375, 2002.

58. Barbour KW, Goodwin RL, Guillonneau F, Wang Y, Baumann H and Berger FG: Functional diversification during evolution of the murine alpha(1)-proteinase inhibitor family: role of the hypervariable reactive center loop. Mol Biol Evol 19: 718-727, 2002.

59. Kueppers F and Mills J: Trypsin inhibition by mouse serum: sexual dimorphism controlled by testosterone. Science 219: 182-184, 1983.

60. Yamamoto K and Sinohara H: Regulation by sex hormones of serum levels of contrapsin and alpha 1-antiprotease in the mouse. Biochim Biophys Acta 798: 231-234, 1984.

61. Borriello F and Krauter KS: Multiple murine alpha 1-protease inhibitor genes show unusual evolutionary divergence. Proc Natl Acad Sci USA 88: 9417-9421, 1991. 